\title{
Perception of the risk of tobacco use in pregnancy and factors associated with tobacco use in rural areas of Myanmar
}

\author{
Kyaw L. Show', Aung P. Phyo', Saw Saw', Ko K. Zaw², Thuzar C. Tin³, Nyein A. Tun³, Khin T. Wai'
}

\begin{abstract}
INTRODUCTION Tobacco use is recognized as the most important preventable risk factor for pregnancy complications and undesirable fetal outcomes. This study examined the reported prevalence of tobacco use among married men and women residing in rural areas, and their knowledge on the risks of tobacco use during pregnancy and the factors associated with tobacco use.

METHODS A cross-sectional study was conducted within 32 villages in the delta region of Myanmar, randomly selected through multistage sampling procedure by using a pre-tested structured questionnaire during 2016. In all, 617 people participated in the household survey.

RESULTS About $80 \%$ of current smokers (109/128) smoked at home, of whom 16\% reported the presence of a pregnant woman in their smoking area. Less than $25 \%$ of the respondents were aware of the negative impacts of tobacco use on pregnancy outcomes. Men had significantly lower perceived risk towards smoking on some pregnancy outcomes. Multivariate analysis confirmed the significant influence of male gender (adjusted OR, AOR $=12.62$; 95\% CI: 6.30-25.29) and the age of women $<35$ years ( $\mathrm{AOR}=3.51 ; 95 \% \mathrm{CI}: 1.97-6.26)$ on current tobacco use, when controlling for other variables.

ConcLusions Men in the study villages and those with a low level of education had poor knowledge on the risks of tobacco on pregnancy outcomes. However, good knowledge and perceived risk of undesirable impacts on pregnancy did not have any influence on tobacco use.
\end{abstract}

\section{AFFILIATION \\ 1 Department of Medical Research, Ministry of Health and Sports, Yangon, Myanmar 2 University of Public Health, Yangon, Myanmar 3 Department of Public Health, Ministry of Health and Sports, Naypyitaw, Myanmar}

\section{CORRESPONDENCE TO}

Kyaw L. Show. Department of Medical Research, Ministry of Health and Sports, Yangon, Myanmar. E-mail: kyawlwins@ gmail.com ORCID ID: https://orcid. org/0000-0001-9349-5134

\section{KEYWORDS}

pregnancy, tobacco, rural, perception

Received: 27 November 2018

Revised: 30 September 2019

Accepted: 1 October 2019

\section{INTRODUCTION}

Tobacco use is a major public health concern globally. It is the most important preventable risk factor for pregnancy complications and dangerous fetal outcomes $^{1}$; cigarette smoking poses a threat both to pregnant women and their newborns, such as tobaccoinduced abortions and deaths from perinatal disorders. Also, smokeless tobacco use during pregnancy can have a higher risk of pregnancy complications with unfavorable fetal outcomes. Moreover, maternal exposure to secondhand smoke (SHS) in pregnancy may affect the birth-weight of newborns ${ }^{2-5}$. Studies from Asia and Sub-Saharan Africa indicate an increased risk of infant and child mortality due to tobacco smoke exposure ${ }^{6,7}$. Thus, several nations have given priority to the implementation of policies for the prevention of smoking in pregnancy ${ }^{8-11}$. The nationwide survey in 2009 informed of the higher prevalence of current daily smoking and current daily smokeless tobacco use in rural areas compared to urban settings. In Myanmar, the STEP survey in 2014 reported that approximately $26 \%$ of people ( $44 \%$ of men and $8 \%$ of women) were current smokers and about $43 \%$ ( $62 \%$ of men and $24 \%$ of women) were current users of smokeless tobacco ${ }^{12}$. In 2015, a Myanmar Demographic and Health Survey reported that one in 25 of women of reproductive age (1549 years) used either one of the tobacco products ${ }^{13}$. 
Among others, the Ayeyawady Region revealed a high prevalence of tobacco use. The regional prevalence estimates of current daily smoking and current daily smokeless tobacco use were $19.6 \%$ and $30.3 \%$, respectively ${ }^{14}$. Furthermore, the Ayeyawady Region reported an infant mortality rate of 87 per 1000 live births, which ranked second in Myanmar in 2016 and indicated a need to ascertain the underlying causes $^{15}$. The Ministry of Health and Sports (MoHS) of Myanmar has pointed to the dangers of tobacco use on pregnancy complications and unfavorable fetal outcomes through health information, education and communication materials ${ }^{16}$.

Risk perception is critical for the decision of smokers to quit smoking, as noted in several studies in developed countries ${ }^{17-19}$. However, there are no studies on the influence of knowledge and perceived risks towards the use of tobacco among adults in rural areas of Myanmar. This is an underresearched area in how people perceive the risks of harmful substances that may affect their use. Further knowledge on risk perception is required to design health promotion programs. The present study attempted to examine the reported prevalence of smoking and smokeless tobacco use among married men and women residing in rural areas, and their knowledge of the risks in pregnancy due to tobacco use. The overall aim was to provide evidence to inform public health programs on reducing the infant mortality rate through tobacco cessation as the essential strategy.

\section{METHODS}

\section{Study design}

We conducted a cross-sectional household study in 32 villages of Kyaunggon and Lemyethna townships in the Ayeyawady Region of Myanmar from August 2016 to July 2017. Administratively, the Republic of the Union of Myanmar is divided into seven states and seven regions and a Nay Pyi Taw Council Union Territory. Myanmar has an estimated population of 51.5 million according to the 2014 National Census ${ }^{15}$, with nearly $70 \%$ residing in rural areas. The Department of Public Health under the MoHS is responsible for providing primary health care services, including information, education and communication through rural health centers (RHC) and subcenters. The National Census Report 2014 also indicated that
86 in 100 persons from the Ayeyawady Region were rural residents. Altogether 1.1 million out of 1.6 million women aged 15-49 years (reproductive age group) in the Ayeyawady Region were ever married. The study population in the present research covered married women of reproductive age in the range 1849 years and their husbands.

\section{Sample size and sampling procedure}

We assumed the anticipated population proportion of current smokers in Myanmar as 26\% according to the STEP survey $2014^{12}$. Allowing for an error margin of 0.05 at the $95 \%$ confidence interval and a $5 \%$ non-response rate, the required sample size was 320 respondents for married men and women, respectively, for a total of 640 respondents. A multistage sampling procedure was used. In the first stage, the research team purposively included two out of 33 townships in the Ayeyawady Region. Then, two rural health centers (RHCs) from each township were randomly selected. Next, under the jurisdiction of each RHC, a two-way stratification method was used to avoid selection bias and included four villages with Sub-RHC and four villages without Sub-RHC, randomly. This two-way stratification procedure allowed us to attain the unbiased estimates without a need to consider for design effect ${ }^{20}$. Finally, ten men and ten women per study site were selected at random to meet the required sample size. Owing to limited resources, the survey team was unable to meet the standard sample size of 20 per gender category in each site. Local administrative authorities provided the list of eligible households in selected sites. If the eligible person was not available during the household visit between 9 am and $5 \mathrm{pm}$, the team used the nearest eligible household. There were no callbacks during the field survey due to time constraints. In all, 617 out of 640 eligible respondents $(96.4 \%)$ participated in the household survey. The non-response rate in this study only referred to refusals to participate in the survey.

\section{Data collection}

Following written informed consent, trained interviewers administered a pre-tested structured questionnaire during face-to-face interviews with one eligible participant per selected household. The pre-tested and modified structured interview 
questionnaire covered four components: sociodemographic characteristics; awareness on the miscarriages and fetal outcomes due to tobacco (smoked tobacco, smokeless tobacco, and secondhand tobacco smoke) on pregnancy; their perceptions measured by three categorical items 'yes', 'no', and 'do not know'; and practices. Current smokers and smokeless tobacco users were defined as the people who smoked cigarettes/used smokeless tobacco on a daily basis and occasionally. Only women were asked for perceived risks due to smokeless tobacco. Exposure to SHS was defined as tobacco smoke that was exhaled by a smoker and was inhaled by persons nearby.

\section{Data analysis}

After checking for consistency and completeness, collected data were entered by Epi-data version 3.2 (EpiData Association, Denmark) and analyzed by IBM SPSS Statistics version 22.0 (SPSS, Inc., Chicago IL, USA). The reported prevalence rates and $95 \%$ CIs were computed. Accordingly, the level of knowledge as the first outcome measure of interest was categorized as 'poor' for respondents who scored $\leq$ mean value and 'good' for those who scored $>$ mean value. We transformed a 'yes' response to perception questions of five possible pregnancy risks: miscarriages, preterm, low birth weight babies, stillbirth, and congenital anomalies into one composite measure of perception to smoking, smokeless tobacco or SHS exposure. Current smoking by both married men and women and current smokeless tobacco use (only for women) were additional outcome measures that were dichotomized into 'yes' and 'no' categories. For crosstabulations, the chi-squared test was used to assess the contribution of sociodemographic characteristics on differences in outcome measures and a $p<0.05$ was considered statistically significant. Simple logistic regressions were performed to determine the factors associated with the levels of knowledge scores and current tobacco use when adjusted for confounders.

We obtained ethics approval from Ethics Review Committee, Department of Medical Research, Ministry of Health and Sports, Myanmar (Ethics/ DMR/2016/088, dated 4 July 2016). Privacy, confidentiality and anonymity issues were taken into account according to the Helsinki Declaration.

\section{RESULTS}

The average age of the respondents was 35.6 years (95\% CI: 35.0-36.2) and nearly $80 \%$ had low formal education (middle school level education and below). Four in five respondents were employed and more than half had a monthly family income of more than 100000 Kyat (approximately US\$80). One in five respondents was a current smoker and cheroots predominated as the most commonly used product (a little cigar-like tobacco product). Males were significantly more likely than females to smoke cigarettes/cheroots (38.5\% vs $3.8 \%)$ and use smokeless tobacco $(73.1 \%$ vs $23.4 \%)$. The majority of current smokers $(85.2 \%)$ smoked at home and $16.4 \%$ reported that there was a pregnant woman in their smoking area. Nearly half of the respondents currently used smokeless tobacco daily.

Table 1 presents the knowledge of the participants with regard to pregnancy outcomes due to

Table 1. Knowledge on the risks of tobacco use on pregnancy outcomes among married men and women, 32 villages, Ayeyawady Region, 2016

\begin{tabular}{|c|c|c|c|c|}
\hline KVOIVLEDGE & $\begin{array}{c}\text { Total } \\
(\mathrm{n}-617) \\
\text { n }(\%)\end{array}$ & $\begin{array}{c}\text { Vale } \\
(\mathrm{n}=301) \\
\mathrm{n}(\%)\end{array}$ & $\begin{array}{c}\text { Female } \\
(\mathrm{n}=316) \\
\text { n }(\%)\end{array}$ & $p$ \\
\hline \multicolumn{5}{|c|}{ Knowledge on the risk of smoking on pregnancy outcomes } \\
\hline Abortion & $88(14.3)$ & $33(11.0)$ & 55 (17.4) & 0.022 \\
\hline Pre-term & $124(20.1)$ & $41(13.6)$ & $83(26.3)$ & $<0.001$ \\
\hline LBW baby & $145(23.5)$ & 46 (15.3) & 99 (31.3) & $<0.001$ \\
\hline Stillbirth & $24(3.9)$ & $8(2.7)$ & $16(5.1)$ & 0.122 \\
\hline Congenital & $50(8.1)$ & $20(6.6)$ & $30(9.5)$ & 0.195 \\
\hline
\end{tabular}
anomalies

Knowledge on the risk of secondhand smoke exposure on pregnancy outcomes

$\begin{array}{lcccr}\text { Abortion } & 63(10.2) & 23(7.6) & 40(12.7) & 0.040 \\ \text { Pre-term } & 124(20.1) & 46(15.3) & 78(24.7) & 0.004 \\ \text { LBW baby } & 135(21.9) & 43(14.3) & 92(29.1) & <0.001 \\ \text { Stillbirth } & 12(1.9) & 5(1.7) & 7(2.2) & 0.618 \\ \text { Congenital } & 37(6.0) & 15(5.0) & 22(7.0) & 0.301\end{array}$
anomalies

Knowledge on the risk of smokeless tobacco use on pregnancy outcomes

$\begin{array}{lllll}\text { Abortion } & 49(7.9) & 18(6.0) & 31(9.8) & 0.079\end{array}$

Pre-term $\quad 116(18.8) \quad 37(12.3) \quad 79(25.0)<0.001$

LBW baby $\quad 139(22.5) \quad 42(14.0) \quad 97(30.7)<0.001$

Stillbirth $\quad 15(2.4) \quad 5(1.7) \quad 10(3.2) \quad 0.226$

$\begin{array}{lllll}\text { Congenital } & 28(4.5) & 11(3.7) & 17(5.4) & 0.303\end{array}$

anomalies

* Single item positive responses only. LBW: low birth weight. 
Table 2. Perceived risks of tobacco use on pregnancy outcomes among married men and women, 32 villages, Ayeyawady Region, 2016

\begin{tabular}{|c|c|c|c|c|}
\hline PERCEPTIONS * & $\begin{array}{c}\text { Total } \\
(\mathrm{n}=617) \\
\text { in }(\%)\end{array}$ & $\begin{array}{c}\text { Vale } \\
(\mathrm{n}=301) \\
\text { n }(\%)\end{array}$ & $\begin{array}{c}\text { Female } \\
(\text { In } 316) \\
\text { In }(\%)\end{array}$ & $p$ \\
\hline
\end{tabular}

Perceived risk of smoking on pregnancy outcomes

$\begin{array}{lllll}\text { Abortion } & 428(69.4) & 197(65.4) & 231(73.1) & 0.039 \\ \text { Pre-term } & 494(80.1) & 229(76.1) & 265(83.9) & 0.016 \\ \text { LBW baby } & 526(86.9) & 252(83.7) & 284(89.9) & 0.024 \\ \text { Stillbirth } & 429(69.5) & 206(68.4) & 223(70.6) & 0.565 \\ \text { Congenital } & 532(86.2) & 259(86.0) & 273(86.4) & 0.901 \\ \text { anomalies } & & & & \end{array}$

Perceived risk of exposure to secondhand smoke on pregnancy outcomes

$\begin{array}{lllll}\text { Abortion } & 392(63.5) & 195(64.8) & 197(62.3) & 0.529 \\ \text { Pre-term } & 454(73.6) & 224(74.4) & 230(72.8) & 0.645 \\ \text { LBW baby } & 492(79.7) & 237(78.7) & 255(80.7) & 0.545 \\ \text { Stillbirth } & 375(60.8) & 187(62.1) & 188(59.5) & 0.503 \\ \text { Congenital } & 488(79.1) & 244(81.1) & 244(77.2) & 0.240\end{array}$

anomalies

Perceived risk of smokeless tobacco use on pregnancy outcomes

Abortion

Pre-term

LBW baby

Stillbirth

Congenital

anomalies

* Single item positive responses only. LBW: low birth weight. tobacco use during pregnancy. The respondents cited low birth weight babies as the commonest consequence of smoking followed by pre-term labor and miscarriages. Married women mentioned the negative outcomes of pregnancy due to tobacco use more specifically than married men.

According to Table 2 , about $65 \%$ to $86 \%$ of men and $71 \%$ to $90 \%$ of women expressed their perceived risks of smoking on miscarriages and fetal outcomes. About $60 \%$ to $80 \%$ of married men and married women had perceived risks of SHS exposure on miscarriages and fetal outcomes. Moreover, 53\% and $73 \%$ of married women perceived the risks of miscarriages and fetal outcomes, respectively, when they used smokeless tobacco.

Table 3 elucidates the factors associated with knowledge concerning the risk of tobacco use on pregnancy outcomes. Multivariate analysis confirmed that being male (AOR=2.96, 95\% CI: 2.05-4.26) was significantly associated with the lack of knowledge of any possible risk of smoking and SHS exposure. Moreover, those who had a higher formal education were more likely to be aware of the risks of smoking to pregnancy, however this difference was not evident for exposure to SHS or the use of smokeless tobacco.

Table 3. Knowledge on the risks of tobacco use on pregnancy outcomes and associated factors among married men and women, 32 villages, Ayeyawady Region, 2016

\begin{tabular}{|c|c|c|c|c|c|c|c|c|c|}
\hline \multirow[t]{2}{*}{ Variables } & \multicolumn{3}{|c|}{ Smoking* } & \multicolumn{3}{|c|}{ Secondhand smoke exposure* } & \multicolumn{3}{|c|}{$\begin{array}{c}\text { Smokeless tobacco use * (for } \\
\text { females only) }\end{array}$} \\
\hline & In $(\%)$ & crude OR & AOR & In $(\%)$ & crude OR & AOR & n $(\%)$ & crude OR & IOR \\
\hline \multicolumn{10}{|l|}{ Gender } \\
\hline $\begin{array}{l}\text { Married men } \\
(n=301)\end{array}$ & $206(68.4)$ & $\begin{array}{c}2.91 \\
(2.09-4.04)\end{array}$ & $\begin{array}{c}2.96 \\
(2.05-4.26)\end{array}$ & $212(70.4)$ & $\begin{array}{c}2.05 \\
(1.47-2.85)\end{array}$ & $\begin{array}{c}2.25 \\
(1.56-3.24)\end{array}$ & NA & NA & NA \\
\hline $\begin{array}{l}\text { Married women } \\
(\mathrm{n}=316)\end{array}$ & $135(42.7)$ & Ref. & Ref. & $170(53.8)$ & Ref. & Ref. & & & \\
\hline \multicolumn{10}{|l|}{ Age group (years) } \\
\hline$>35(n=314)$ & $184(58.6)$ & $\begin{array}{c}1.32 \\
(0.96-1.81)\end{array}$ & $\begin{array}{c}1.21 \\
(0.87-1.69)\end{array}$ & $202(64.3)$ & $\begin{array}{c}1.23 \\
(0.89-1.71)\end{array}$ & $\begin{array}{c}1.18 \\
(0.84-1.65)\end{array}$ & $86(56.2)$ & $\begin{array}{c}1.33 \\
(0.86-2.07)\end{array}$ & $\begin{array}{c}1.34 \\
(0.85-2.10)\end{array}$ \\
\hline $18-35(n=303)$ & $157(51.8)$ & Ref. & Ref. & $180(59.4)$ & Ref. & Ref. & 80 (49.1) & Ref. & Ref. \\
\hline \multicolumn{10}{|l|}{ Education } \\
\hline $\begin{array}{l}\leq \text { Middle school } \\
(\mathrm{n}=473)\end{array}$ & $276(58.4)$ & $\begin{array}{c}1.70 \\
(1.17-2.48)\end{array}$ & $\begin{array}{c}1.73 \\
(1.17-2.57)\end{array}$ & $298(63.0)$ & $\begin{array}{c}1.22 \\
(0.83-1.78)\end{array}$ & $\begin{array}{c}1.27 \\
(0.86-1.88)\end{array}$ & $133(55.2)$ & $\begin{array}{c}1.57 \\
(0.93-2.64)\end{array}$ & $\begin{array}{c}1.65 \\
(0.96-2.84)\end{array}$ \\
\hline $\begin{array}{l}\geq \text { High school } \\
(n=144)\end{array}$ & $65(45.1)$ & Ref. & Ref. & $84(58.3)$ & Ref. & Ref. & $33(44.0)$ & Ref. & Ref. \\
\hline
\end{tabular}


Table 3. Continued

\begin{tabular}{|c|c|c|c|c|c|c|c|c|c|}
\hline \multirow[t]{2}{*}{ Variables } & \multicolumn{3}{|c|}{ Smoking* } & \multicolumn{3}{|c|}{ Secondhand smoke exposure" } & \multicolumn{3}{|c|}{$\begin{array}{l}\text { Smokeless tobaceo use * (for } \\
\text { females only) }\end{array}$} \\
\hline & $n\left(0_{0}^{0}\right)$ & crude OR & AOR & $n(\%)$ & crude OR & AOR & $n(\%)$ & crude OR & AOR \\
\hline \multicolumn{10}{|l|}{ Occupation } \\
\hline Employed $(n=510)$ & $295(57.8)$ & $\begin{array}{c}1.82 \\
(1.19-2.77)\end{array}$ & $\begin{array}{c}0.96 \\
(0.60-1.55)\end{array}$ & $319(62.5)$ & $\begin{array}{c}1.17 \\
(0.76-1.78)\end{array}$ & $\begin{array}{c}0.74 \\
(0.46-1.19)\end{array}$ & $107(50.5)$ & $\begin{array}{c}0.78 \\
(0.49-1.25)\end{array}$ & $\begin{array}{c}0.72 \\
(0.44-1.17)\end{array}$ \\
\hline Dependant $(n=107)$ & $46(43.0)$ & Ref. & Ref. & $63(58.9)$ & Ref. & Ref. & $59(56.7)$ & Ref. & Ref. \\
\hline \multicolumn{10}{|l|}{$\begin{array}{l}\text { Family income } \\
\text { (Kyat) }\end{array}$} \\
\hline$>100000(n=339)$ & $187(55.2)$ & $\begin{array}{c}0.99 \\
(0.72-1.36)\end{array}$ & $\begin{array}{c}1.07 \\
(0.76-1.49)\end{array}$ & $218(64.3)$ & $\begin{array}{c}1.25 \\
(1.90-1.74)\end{array}$ & $\begin{array}{c}1.29 \\
(0.92-1.81)\end{array}$ & $94(53.1)$ & $\begin{array}{c}1.05 \\
(0.67-1.64)\end{array}$ & $\begin{array}{c}1.12 \\
(0.71-1.79)\end{array}$ \\
\hline$\leq 100000(n=278)$ & $154(55.4)$ & Ref. & & Ref. & $164(59.0)$ & Ref. & Ref. & $72(51.8)$ & Ref. \\
\hline
\end{tabular}

${ }^{*}$ Do not know at least one of five possible pregnancy risks: miscarriages, preterm, low birth weight babies, stillbirth, and congenital anomalies. AOR: adjusted odds ratio. Exchange rate: 1000 Kyat about 0.8 US\$.

According to Table 4, it was significantly common for married men to smoke (AOR=12.62; 95\% CI: 6.3025.29) compared to married women, when controlling for other variables. Other sociodemographic differentials, knowledge and risk perception did not have a significant influence on smoking practice.
Table 5 analyzes factors associated with smokeless tobacco use among a subset of married women $(n=316)$. Those in the older age group, i.e. aged $>35$ years, significantly reported the use of smokeless tobacco (AOR=3.51; 95\% CI: 1.97-6.26) compared to younger married women.

Table 4. Current tobacco use and its associated factors among married men and women, 32 villages, Ayeyawady Region, 2016

\begin{tabular}{|c|c|c|c|}
\hline \multirow[t]{2}{*}{ Variables } & \multicolumn{3}{|c|}{ Current smoker } \\
\hline & n $(\%)$ & Crude OR & AOR \\
\hline \multicolumn{4}{|l|}{ Gender } \\
\hline Married women $(n=316)$ & $12(3.8)$ & Ref. & Ref. \\
\hline Married men $(n=301)$ & $116(38.5)$ & $15.86(8.53-29.58)$ & $12.62(6.30-25.29)$ \\
\hline \multicolumn{4}{|l|}{ Age group (years) } \\
\hline $18-35(n=303)$ & $52(17.2)$ & Ref. & Ref. \\
\hline$>35(n=314)$ & $76(24.2)$ & $1.54(1.04-2.29)$ & $1.51(0.96-2.36)$ \\
\hline \multicolumn{4}{|l|}{ Education } \\
\hline$\geq$ High school $(n=144)$ & $29(20.1)$ & Ref. & Ref. \\
\hline$\leq$ Middle school $(n=473)$ & 99 (20.9) & $1.05(0.66-1.67)$ & $0.91(0.53-1.55)$ \\
\hline \multicolumn{4}{|l|}{ Occupation } \\
\hline Dependent $(n=107)$ & $4(3.7)$ & Ref. & Ref. \\
\hline Employed $(n=510)$ & $124(24.3)$ & $8.27(2.98-22.92)$ & $1.41(0.44-4.55)$ \\
\hline \multicolumn{4}{|l|}{ Family income (Kyat) } \\
\hline$>100000(n=339)$ & $65(19.2)$ & Ref. & Ref. \\
\hline$\leq 100000(n=278)$ & $63(22.7)$ & $1.24(0.84-1.82)$ & $1.33(0.85-2.07)$ \\
\hline \multicolumn{4}{|c|}{ Known pregnancy risk due to smoking } \\
\hline At least one $(n=276)$ & $32(11.6)$ & Ref. & Ref. \\
\hline None $(n=341)$ & $96(28.2)$ & $2.99(1.93-4.63)$ & $1.62(0.85-3.08)$ \\
\hline \multicolumn{4}{|c|}{$\begin{array}{l}\text { Known pregnancy risk due to secondhand } \\
\text { smoke exposure }\end{array}$} \\
\hline At least one $(n=235)$ & $30(12.8)$ & Ref. & Ref. \\
\hline None $(n=382)$ & $98(25.7)$ & $2.36(1.51-3.69)$ & $1.27(0.65-2.47)$ \\
\hline
\end{tabular}


Table 4. Continued

\begin{tabular}{|c|c|c|c|}
\hline \multirow[t]{2}{*}{ Variables } & \multicolumn{3}{|c|}{ Current smoker } \\
\hline & In $(\%)$ & Crude OR & AOR \\
\hline \multicolumn{4}{|c|}{ Perceived risk of smoking to pregnancy } \\
\hline Good perception $(n=436)$ & $80(18.3)$ & Ref. & Ref. \\
\hline Poor perception $(n=181)$ & $48(26.5)$ & $1.61(1.07-2.42)$ & $1.49(0.82-2.69)$ \\
\hline \multicolumn{4}{|c|}{$\begin{array}{l}\text { Perceived risk of secondhand smoke exposure } \\
\text { to pregnancy }\end{array}$} \\
\hline Good perception $(n=386)$ & $78(20.2)$ & Ref. & Ref. \\
\hline Poor perception $(n=231)$ & $50(21.6)$ & $1.09(0.73-1.63)$ & $0.83(0.46-1.49)$ \\
\hline
\end{tabular}

Exchange rate: 1000 Kyat about 0.8 US\$. AOR: adjusted odds ratio.

Table 5. Smokeless tobacco practice and its associated factors among married women, 32 villages, Ayeyawady Region, 2016

\begin{tabular}{|c|c|c|c|}
\hline \multirow{2}{*}{ Variables } & \multicolumn{3}{|c|}{ Current smokeless tobacco user } \\
\hline & n $(\%)$ & Crude OR & AOR \\
\hline \multicolumn{4}{|l|}{ Age group (years) } \\
\hline $18-35(n=163)$ & $22(13.5)$ & Ref. & Ref. \\
\hline$>35(n=153)$ & $53(34.6)$ & $3.39(1.94-5.94)$ & $3.51(1.97-6.26)$ \\
\hline \multicolumn{4}{|l|}{ Education } \\
\hline$\geq$ High school $(n=75)$ & $12(16.0)$ & Ref. & Ref. \\
\hline$\leq$ Middle school $(n=241)$ & $63(26.1)$ & $1.86(0.94-3.67)$ & $1.55(0.75-3.22)$ \\
\hline \multicolumn{4}{|l|}{ Occupation } \\
\hline Dependent $(n=104)$ & $18(17.3)$ & Ref. & Ref. \\
\hline Employed $(n=212)$ & $57(26.9)$ & $1.76(0.97-3.18)$ & $1.43(0.76-2.67)$ \\
\hline \multicolumn{4}{|l|}{ Family income (Kyat) } \\
\hline$>100000 \quad(n=177)$ & $36(20.3)$ & Ref. & Ref. \\
\hline$\leq 100000(n=139)$ & $39(28.1)$ & $1.53(0.91-2.57)$ & $1.52(0.87-2.67)$ \\
\hline \multicolumn{4}{|c|}{$\begin{array}{l}\text { Known pregnancy risk due to smokeless } \\
\text { tobacco }\end{array}$} \\
\hline None $(n=166)$ & $36(21.7)$ & Ref. & Ref. \\
\hline At least one $(n=150)$ & $39(26.0)$ & $1.27(0.76-2.13)$ & $1.37(0.78-2.41)$ \\
\hline \multicolumn{4}{|c|}{$\begin{array}{l}\text { Perceived risk of smokeless tobacco to } \\
\text { pregnancy }\end{array}$} \\
\hline Poor perception $(n=147)$ & $31(21.1)$ & Ref. & Ref. \\
\hline Good perception $(n=169)$ & $44(26.0)$ & $1.32(0.78-2.23)$ & $1.25(0.71-2.19)$ \\
\hline
\end{tabular}

Exchange rate: 1000 Kyat about 0.8 US\$. AOR: adjusted odds ratio

\section{DISCUSSION}

To the best of our knowledge, this is the first study in Myanmar that specifically explored the knowledge and risk perceptions and associated factors of tobacco use among married men and women. There was a moderate degree of reported smoking and the use of smokeless tobacco, especially among men who were married to women of reproductive age in rural areas of the Ayeyawady Region. The prevalence of using tobacco (both smoked and smokeless forms) ranged between $21 \%$ and $48 \%$, respectively, among married men and women (combined) in rural areas. One study in the Yangon Region in Myanmar reported that the prevalence of smokeless tobacco use in rural households was approximately $38 \%{ }^{21}$. The overall reported prevalences in this study were similar to those of the nationwide STEP survey report (2014), $20.7 \%$ vs $26.1 \%$ current smokers, and $47.6 \%$ vs $43.2 \%$ currently using smokeless tobacco ${ }^{12}$. However, a meta-analysis study performed in Myanmar by Kyaing 
et al. ${ }^{22}$ in 2012 reported a lower prevalence of $20.8 \%$ compared to our study. Even though different surveys used different data collection methods, the reported prevalence of tobacco use did not vary widely. Furthermore, the results clearly indicate that tobacco use was predominant among males in all studies mentioned above. In 2012, the prevalence estimates of current smokers was $46 \%$ of males and $5 \%$ of females among ASEAN countries, and $37 \%$ of men and $7 \%$ of women globally ${ }^{23,24}$. Even though smokeless tobacco practice was popular among men in most SouthEast Asian countries, women were more likely to use smokeless tobacco in Bangladesh, Indonesia and Thailand ${ }^{25,26}$ and the reverse was true in the present study among married people in rural areas.

It is well documented that tobacco use in either smoked or smokeless form can harm not only the pregnancy but also the fetus $\mathrm{s}^{3,5,8,27,28}$. However, in this study, less than $25 \%$ (lowest of $1.9 \%$ to highest of $23.5 \%$ ) of respondents in rural areas mentioned the negative impact of tobacco use on pregnancy outcomes, which was unsatisfactory. Addressing knowledge of smoking risks and cessation counseling in indigenous communities is a priority for antenatal programs ${ }^{29}$. Married men had significantly lower knowledge of the negative impact of tobacco use on pregnancy outcomes compared to women. In addition, low formal education had a significant influence on poor knowledge. This finding highlights the necessity to seek more effective channels to convey health information to married people from rural areas on risks of tobacco on miscarriages and fetal outcomes.

\section{Limitations}

Despite the fact that women could express at a better level than men the perceived risks on the effects of smoking on miscarriages and fetal outcomes, the influence of knowledge and risk perception on tobacco use was not significant in this study. This might be due to underreporting of tobacco use or the sample size was small. Besides, under-reporting of tobacco use among female respondents was more likely, especially cigarette smoking, compared to men.

This study was conducted in 32 villages in two townships of the Ayeyawady Region and hence cannot be generalized to all rural married people of Myanmar. Above all, there was the possibility of social desirability bias related to positive responses towards knowledge and risk perceptions.

\section{CONCLUSIONS}

Translation of evidence-based findings and strengthening knowledge transfer mechanisms of correct information to prevent tobacco exposure in pregnancy through effective risk communication programs is critical in promoting maternal and newborn health ${ }^{5,30}$. Conversely, concerted efforts to engage stakeholders are essential to introduce cost-effective prevention strategies to mitigate the negative impact of tobacco on pregnancy outcomes in a developing country like Myanmar. Men in study villages and those with a low level of education had poor knowledge on the risks of tobacco on pregnancy outcomes. However, good knowledge and perceived risk of undesirable impacts in pregnancy did not have any influence on tobacco use. Nevertheless, intensification of targeted health promotion programs by innovative approaches in rural areas, alongside tobacco regulations, is indispensable to reduce the prevalence of both smoke and smokeless tobacco use.

\section{REFERENCES}

1. World Health Organization. WHO global report on trends in prevalence of tobacco smoking 2015. Switzerland: World Health Organization; 2015. https://apps.who.int/iris/ bitstream/handle/10665/156262/9789241564922_eng. pdf;jsessionid=00F592D4ADB012F82C2A06B2 B09A121D? sequence=1. Accessed September 30, 2019.

2. Wickström R. Effects of Nicotine During Pregnancy : Human and Experimental Evidence. Curr Neupharmacol. 2007;5(3):213-222. doi:10.2174/157015907781695955

3. Hoque M, Rahman E, Dey PR. Pregnancy Outcome of Mothers who Used Smokeless Tobacco for Five Years or More. Bangladesh Journal of Child Health. 2011;35(1):610. doi:10.3329/bjch.v35i1.10366

4. World Health Organization. Regional Strategy for Tobacco Control. New Delhi: World Health Organization; 2012. https://apps.who.int/iris/bitstream/handle/10665/205847/ B0273.pdf?sequence $=1 \&$ cisAllowed=y. Accesses September $30,2019$.

5. World Health Organization. WHO recommendations for the prevention and management of tobacco use and second-hand smoke exposure in pregnancy. Geneva: World Health Organization; 2013. https://apps.who.int/ iris/bitstream/handle/10665/94555/9789241506076_ eng.pdf?sequence=1. Accessed September 30, 2019.

6. Semba RD, de Pee S, Sun K, Best CM, Sari M, Bloem MW. Paternal smoking and increased risk 
of infant and under-5 child mortality in Indonesia. Am J Public Health. 2008;98(10):1824-1826. doi:10.2105/AJPH.2007.119289

7. Owili PO, Muga MA, Pan WC, Kuo HW. Indoor secondhand tobacco smoke and risk of under-five mortality in 23 sub-Saharan Africa countries: A population based study and meta-analysis. PLoS One. 2017;12(5):1-17. doi:10.1371/journal.pone.0177271

8. UK Center for Tobacco Control Studies. Tackling smoking in pregnancy in Scotland : a policy summit. Edinburgh: University of Edinburgh; 2012. https://www.ashscotland. org.uk/media/5568/Tackling\%20smoking\%20in $\% 20$ pregnancy; $\% 20$ summit $\% 20041012 \% 20$ report.doc.pdf. Accessed September 30, 2019.

9. Bennett L, Grant A, Jones S, et al. Models for Access to Maternal Smoking cessation Support (MAMSS): A study protocol of a quasi-experiment to increase the engagement of pregnant women who smoke in NHS Stop Smoking Services. BMC Public Health. 2014;14(1):1-8. doi:10.1186/1471-2458-14-1041

10. Jones M, Lewis S, Parrott S, Coleman T. Systematic critical review of previous economic evaluations of smoking cessation during pregnancy. BMJ Open. 2015;5(11):e008998. doi:10.1136/bmjopen-2015-008998

11. Bell R, Glinianaia SV, Van Der Waal Z, et al. Evaluation of a complex healthcare intervention to increase smoking cessation in pregnant women: Interrupted time series analysis with economic evaluation. Tob Control. 2018;27(1):90-98. doi:10.1136/tobaccocontrol-2016-053476

12. World Health Organization, Myanmar Ministry of Health. National survey of Diabetes Mellitus and risk factors for NCD in Myanmar. Yangon: Worls Health Organization, Myanmar Ministry of Health; 2014. https://www.medbox. org/myanmar/report-on-national-survey-of-diabetesmellitus-and-risk-factors-for-non-communicablediseases-ncds-in-myanmar/preview? $q=$. Accessed September 30, 2019.

13. Ministry of Health and Sports, ICF. Myanmar Demographic and Health Survey 2015-2016. Nay Pyi Taw, Myanmar, Rockville, Maryland USA: Ministry of Health and Sports, ICF; 2017. https://dhsprogram.com/ pubs/pdf/FR324/FR324.pdf. Accessed September 30, 2019.

14. Htike MMT, Latt TS, Khine NN, et al. Smoking and smokeless tobacco use in Myanmar: National and regional levels in 2009. Myanmar Heal Res Congr. 2010:15-6.

15. Ministry of Labour Immigration and Population. Thematic Report on mortality. Nay Pyi Taw, Myanmar: Department of Population Ministry of Labour, Immigration and Population; 2017. https://myanmar.unfpa.org/sites/ default/files/pub-pdf/4B_Mortality.pdf. Accessed September 30, 2019.

16. Ministry of Health and Sports. Standardized Health Messages. Nay Pyi Taw, Myanmar: Department of Public Health, Ministry of Health and Sports; 2018.
17. Williams RJ, Herzog TA, Simmons VN. Risk perception and motivation to quit smoking: a partial test of the Health Action Process Approach. Addict Behav. 2011;36(7):789791. doi:10.1016/j.addbeh.2011.03.003

18. FitzGerald JM, Poureslami I, Shum J. Assessing beliefs and risk perceptions on smoking and smoking cessation in immigrant Chinese adult smokers residing in Vancouver, Canada: a cross-sectional study. BMJ Open. 2015;5(2):e006435. doi:10.1136/bmjopen-2014-006435

19. Krosnick JA, Malhotra N, Mo CH, Bruera E, Chang LC, Pasek J, Randall T. Perceptions of health risks of cigarette smoking: A new measure reveals widespread misunderstanding. PLoS One. 2017;12(8):e0182063. doi:10.1371/journal.pone.0182063

20. Winkler WE. Multi-Way Survey Stratification and Sampling. Washington DC, United States: Statistical Research Division, U.S. Bureau of the Census; 2001. https://www.census.gov/srd/papers/pdf/rrs2001-1.pdf. Accessed September 30, 2019.

21. Wai KT, Maung TM, Naing PA, Show KL. Tackling Household Risk Behaviors as Potential Challenges in Strengthening Primary Health Care in ResourceConstrained Settings: A Cross-Sectional Study. Int J Public Heal Saf. 2018;3(3):1-7. https://www.omicsonline. org/open-access-pdfs/tackling-household-risk-behaviorsas-potential-challenges-instrengthening-primary-healthcare-in-resourceconstrained-settings-acro.pdf. Accessed September 30, 2019.

22. Kyaing N, Sein T, Sein A, Tun A, Shein NN. Smokeless tobacco use in Myanmar. Indian J Cancer. 2012;49(4):347. doi:10.4103/0019-509X.107727

23. Vietnam Steering Committee on Smoking and Health, Southeast Asia Tobacco Control Alliance. The ASEAN Tobacco Control Report. 2012. https://seatca.org/ dmdocuments/ASEAN\%20Tobacco\%20Control\%20 Report\%202012.pdf. September 30, 2019.

24. World Bank. Smoking prevalence, males (\% of adults). World Health Organization; 2016. https://data. worldbank.org/indicator/SH.PRV.SMOK.MA. Accessed January 30, 2019.

25. Flora MS, Mascie-Taylor CGN, Rahman M. Gender and locality differences in tobacco prevalence among adult Bangladeshis. Tob Control. 2009;18(6):445-450. doi:10.1136/tc.2008.028142

26. Sinha D, Gupta P, Ray C, Singh PK. Prevalence of smokeless tobacco use among adults in WHO South-East Asia. Indian J Cancer. 2012;49(4):342. doi:10.4103/0019-509X.107726

27. Hammoud AO, Bujold E, Sorokin Y, Schild C, Krapp M, Baumann P. Smoking in pregnancy revisited: Findings from a large population-based study. Am J Obstet Gynecol. 2005;192(6):1856-1862. doi:10.1016/j.ajog.2004.12.057

28. Salihu HM, Wilson RE. Epidemiology of prenatal smoking and perinatal outcomes. Early Hum Dev. 2007;83(11):713720. doi:10.1016/j.earlhumdev.2007.08.002 
29. Passey ME, D'Este CA, Sanson-Fisher RW. Knowledge, attitudes and other factors associated with assessment of tobacco smoking among pregnant Aboriginal women by health care providers: a cross-sectional survey. BMC Public Health. 2012;12(1):165. doi:10.1186/1471-2458-12-165

30. Miyazaki Y, Hayashi K, Imazeki S. Smoking cessation in pregnancy: psychosocial interventions and patientfocused perspectives. Int J Womens Health. 2015;7:415427. doi:10.2147/IJWH.S54599

ACKNOWLEDGEMENTS

We thank the World Health Organization (WHO) for funding support to conduct this study. We would like to express our sincerest gratitude and respect to our colleagues and interviewers for their great efforts in this study. We also express our deep appreciation to Thae Maung Maung and Wai Wai Han for their valuable comments and efforts in writing this paper. The assistance of the Public Health Director, Township Medical Officers, Staff from the study areas and participants is greatly appreciated.

\section{CONFLICTS OF INTEREST}

The authors have completed and submitted the ICMJE Form for Disclosure of Potential Conflicts of Interest and none was reported.

FUNDING

This work was supported by the World Health Organization (WHO) Reference SEMMR 1611892 Task 5.18 Award 63919.

PROVENANCE AND PEER REVIEW

Not commissioned; externally peer reviewed. 